\title{
Relationship of Udder Morphometric Traits to Mothering Ability of Landrace X Large White Primiparous Sows
}

\author{
J. M. D. Dominguez, J. E. S. Manzanero, C. A. Lontoc-Junsay, \& P. P. Sangel* \\ Institute of Animal Science, College of Agriculture and Food Science, University of the Philippines Los Banos, \\ College, Laguna, Philippines \\ *Corresponding author: ppsangel@up.edu.ph \\ (Received 17-09-2019; Revised 02-12-2019; Accepted 21-01-2020)
}

\begin{abstract}
The use of udder morphometry is often neglected during the selection of replacement gilts. This study was aimed to characterize the udder morphometry of primiparous Landrace $x$ Large White sows across different production stages; and to show its relationship to some mothering ability traits. A total of 20 primiparous Landrace $x$ Large White sows were bred. For each sow, the udder morphometry was characterized by measuring traits like teat tip diameter (DIA), teat length (LEN), inter-teat distance on the same row (SAMER), adjacent teat base distance on opposite row (OPPR), and teat tip to floor distance (FLO) during pre-breeding, post-breeding, and post-farrowing stages. A comparison of observed traits was also made between left and right udders as well as between anterior and posterior udders. Furthermore, the relationship between mothering ability and udder morphometry was evaluated using correlation and regression analyses. Across stages, udder traits were symmetric; however, higher values were measured for traits in posterior than in anterior udders. In the pre-breeding stage, OPPR and FLO of the anterior part had moderate negative correlations to average weaning weight (AWWt) and average daily gain (ADG). On the other hand, in the post-breeding stage, OPPR of the posterior part had a moderate positive correlation to litter size born alive (LSBA) but had a moderate negative correlation to average birth weight (ABWt). Furthermore, IgG content in the colostrum had a strong positive correlation to SAMER of the anterior part but had a strong negative correlation to FLO of the anterior part. It can be concluded that the pre-breeding combined with postbreeding udder morphometry measurements in gilts is useful as a predictor of sow mothering ability. These traits can be included in the criteria when selecting replacement gilts to enhance the productivity of sow herd.
\end{abstract}

Keywords: physical selection; replacement gilts; udder morphometry; mothering ability

\section{INTRODUCTION}

In commercial pig production, the main role of the sow is to rear piglets and have a high number of weaned pigs (Koketsu et al., 2017). Hence, most genetic improvements in dam lines are focused on increasing the litter size (Norsvin, 2014). However, the increase in the number of piglets will become meaningless without also selecting for good mothering ability (Rydhmer 2000). Good mothering ability refers to sow behavior or other related traits that prevent crushing and allow easy teat access to nursing pigs. Thus, udder conformation plays a vital role in this condition. Currently, sows have larger body size and have higher number of litter size but with sub-optimal udder conformations (Vasdal \& Andersen, 2012). This condition leads to the increase in sibling competition during the suckling period because of the different distances between teats in anterior and posterior regions of the udder (Ocepek et al., 2016). As the litter size increases, there is also a high demand for the understanding of the mammary development and number of functional teats, which are both needed to be able to produce good quality colostrum and a high suckling piglet performance (Chalkias et al., 2013; Farmer et al., 2017).

Gilts are the foundation of efficient breeding herd performance (Patterson \& Foxcroft, 2019). However, before entering the breeding population, all replacement gilts are only indirectly measured on maternal capacities such as the total number of teat and the number of functional teats (Norsvin, 2014). Furthermore, the other aspects of udder quality such as udder morphometry, are largely uninvestigated.

Several studies determine the relationship of udder conformation traits to milk production in livestock such as in sheep (Huntley et al., 2012), cattle (Zwertvaegher et al., 2011), and goat (Kouri et al., 2019). However, studies on evaluating the relationship between mothering ability and udder morphometry in livestock are still limited. Such studies can be useful in identifying new candidate traits to be included in genetic improvement programs. In pigs, a series of studies conducted by Balzani et al. (2016a, 2016b, 2016c) showed that the udder morphometry of Large White $x$ Landrace sow has an effect on its 
mothering ability, where udder morphometry can be used as a part of the selection criteria which can contribute to the long-term success and productivity of the sow herd. Moreover, emphasis was given to the further investigation of udder morphometry using a wider range of pure and cross breed pigs.

Hence, this study was aimed to characterize the udder morphometry of primiparous Landrace $x$ Large White sows across different production stages; and to show its relationship to some mothering ability traits. Moreover, the study hypothesized that there are differences between the anterior and posterior part of the sow udder morphometry. Lastly, the study also hypothesized that pre-breeding and post-breeding udder morphometric traits can be used as a predictor of mothering ability in replacement gilts.

\section{MATERIALS AND METHODS}

Experimental procedures were approved by the Animal Care and Use Committee of the University of the Philippines Los Baños (UPLB) with assigned protocol number CAFS-2018-008.

\section{Animals and Management}

The study randomly chose 20 eight-month-old crossbred gilts (Landrace x Large White) with 120-130 $\mathrm{kg}$ live weight. The experiment was conducted at the University Animal Farm (UAF), Institute of Animal Science (IAS), College of Agriculture and Food Science (CAFS), University of the Philippines Los Baños (UPLB).

Animals were managed according to the standard procedures in a commercial swine operation. Feeding was based on the requirements for the particular swine production phase (PHILSAN, 2010). All animals had ad libitum access to water.

Gilts were inseminated with semen from a synthetic sire line. Gestating animals were transferred from the gestation house to the farrowing unit at $110 \mathrm{~d}$ postbreeding, and each farrowing pen consists of a piglet and a sow area. The piglet area, which is inaccessible to the sow, has a feeder and a creep feeding area with an overlaid heating lamp. On the other hand, the sow area was installed with a feeder, nipple water drinker, and has slatted flooring.

During parturition, farrowing assistance was given when needed. Oxytocin was injected only in the case when birth assistance was not enough. No other routines were performed. After parturition, sows were fed with a standard lactation concentrated diet. On d 1 postpartum, standard piglet processing was conducted. After $30 \mathrm{~d}$ postpartum, piglets were weaned and transferred to the weanling section.

\section{Data Gathered}

Udder measurements. The methodology in measuring the parameters was derived from Balzani et al. (2015). The animals were evaluated for five udder conformation traits (Table 1), which were measured in three different production stages: pre-breeding period - one day before breeding, post-breeding - 21 days after confirmed pregnancy, and post-farrowing period - immediately taken after the birth of the first piglet and before the neonates were allowed to suckle colostrum. Four teats were measured in each animal - teat pair located most anterior and teat pair most posterior. Moreover, to assess the symmetry of the teats, side of the teats were also noted (Left or Right). The sows were measured only in standing position because of the constraint in their anatomies and their behaviors, which can prevent measurements.

Colostrum collection and analysis. After giving birth to the first piglet, colostrum samples were collected until 12 hours after farrowing. The samples were collected from the first and last pair of teats specifically from the most anterior and most posterior pairs and were immediately stored at $-20{ }^{\circ} \mathrm{C}$ for future analysis. Oxytocin was also administered during the collection to induce colostrum ejection. The procedure for the detection of immunoglobulin $\mathrm{G}(\mathrm{IgG})$ in colostrum was derived from Balzani et al. (2015). A Brix refractometer was calibrated with distilled water before each set of analyses. A drop of well-mixed colostrum was placed on the Brix refractometer prism and the Brix percentage was recorded as IgG level.

Mothering ability. To assess the performance of the sow, data on litter size, average daily gain (ADG), average birth weight $(\mathrm{ABWt})$, average weaning weight $(\mathrm{AWW})$, and pre-weaning mortality (PWM) rate were collected.

\section{Statistical Analysis}

All data of sow udder morphometry were separately analyzed for each of the respective stages (i.e. prebreeding, post-breeding, or post-farrowing) by using the fixed-effects linear model on teat pair position, udder symmetry, and their interactions. The linear model was as follows:

$$
y_{i j k}=\mu+P_{i}+S_{j}+(P S)_{i j}+e_{i j k}
$$

where: $y_{i j k}$ is the udder morphometry, $\mu$ is the overall mean, $\mathrm{P}_{\mathrm{i}}$ is the effect of $\mathrm{i}^{\text {th }}$ teat pair position, $\mathrm{S}_{\mathrm{i}}$ is the effect of $j^{\text {th }}$ udder symmetry, (PS) is the interaction effect, and $\mathrm{e}_{\mathrm{ijk}}$ is the error term.

Furthermore, the correlation between the udder conformation traits and the sow's mothering ability were analyzed using the Pearson correlation, which was

Table 1. Definition of the measurements of the udder conformation traits

\begin{tabular}{ll}
\hline Traits & Definition \\
\hline LEN & Length of the teat from the base to the tip \\
DIA & Diameter of the teat tip \\
SAMER & $\begin{array}{l}\text { Inter-teat distance between adjacent teat bases in } \\
\text { the same row }\end{array}$ \\
OPPR & $\begin{array}{l}\text { Distance between adjacent teat base in the oppo- } \\
\text { site row }\end{array}$ \\
FLO & Distance between the teat tip and the open floor \\
\hline
\end{tabular}


done separately for each teat pair position and stage. The prediction model of sow mothering ability was developed by using the pre-breeding and post-breeding udder morphometry of experimental gilts as predictor variables. The best regression model was determined using $\mathrm{R}^{2}$ and the significance level was set at $\alpha=0.05$. All data analyses were conducted using SAS University (SAS, 2016).

\section{RESULTS}

\section{Sources of Variation in Udder Morphometry of Primiparous Sows}

Descriptive statistics for udder morphometry and mothering ability are presented in Tables 2 and 3, respectively. Coefficients of variation of udder morphometry in different stages were low to medium $(3.80 \%$ to $26.42 \%$ ). DIA and FLO were consistently more uniform across stages. On the other hand, LEN and SAMER were consistently exhibiting more significant variability across stages. It was also observed that the udder morphometry measurements were not significantly affected by the interaction effect between udder symmetry and teat pair position. Moreover, left and right udder morphometries from pre-breeding to post-farrowing stages were found to be symmetric.

Teat pair position was associated with different udder morphometries across stages (Table 4). In the pre-breeding stage, LEN, SAMER, and FLO were significantly higher $(\mathrm{p}<0.05)$ in the posterior compared to the anterior part. However, DIA and OPPR were the same in both parts. On the other hand, in the post-breeding stage, LEN, SAMER, and FLO were significantly higher $(p<0.05)$ in the posterior compared to the anterior part. However, DIA and OPPR were the same in both parts. Lastly, in the post-farrowing stage, DIA, LEN, SAMER, and FLO were significantly higher $(p<0.05)$ in the posterior compared to the anterior part. In contrast, OPPR was the same in both parts.

\section{Relationship of Post-Farrowing Udder Morphometry to Mothering Ability}

The udder morphometry taken during the postfarrowing stage was subjected to correlation analysis with mothering ability (Table 5). LEN in the anterior part had strong and moderate negative correlations to pre-weaning ADG $(r=-0.53)$ and litter weaning weight $(-0.50)$, respectively.

For the litter size born alive, there was a strong negative correlation to FLO $(\mathrm{r}=0.60)$ in the anterior part. However, there was no significant correlation observed between udder morphometry to litter birth weight and pre-weaning mortality. Lastly, there is also a moderate negative correlation between FLO in the posterior part and colostrum IgG content ( $\mathrm{r}=-0.53)$.

\section{Prediction Equation}

There were significant correlations $(p<0.05)$ between udder morphometry measured during the pre-breeding and post-breeding stages to some mothering abilities (Table 5). In the pre-breeding stage, OPPR and FLO of the anterior part had moderate negative correlations to AWWt and ADG. On the other hand, in the post-breeding stage, OPPR of the posterior part had a moderate positive correlation to LSBA (0.47) but had a moderate negative correlation to ABWt (-0.55). Furthermore, IgG content in the colostrum had a strong positive correlation to SAMER of the anterior part (0.69) but had a strong negative correlation to FLO of the anterior part $(-0.64)$.

The current study took advantage of those significant relationships and developed different equations to predict the mothering ability of Landrace $x$ Large White replacement gilts. Significant regression models $(p<0.05)$ are presented in Table 4. Among the udder

Table 3. Descriptive statistics of mothering ability of Landrace $x$ Large White primiparous sows

\begin{tabular}{lrrrr}
\hline $\begin{array}{c}\text { Mothering } \\
\text { ability }\end{array}$ & Mean & SD & Min & Max \\
\hline LSBA & 10.00 & 2.00 & 6.00 & 14.00 \\
ABWt $(\mathrm{kg})$ & 1.59 & 0.17 & 1.14 & 1.95 \\
ADG $(\mathrm{kg} / \mathrm{d})$ & 0.22 & 0.05 & 0.15 & 0.35 \\
AWWt $(\mathrm{kg})$ & 8.20 & 1.66 & 5.68 & 12.22 \\
PWM $(\%)$ & 0.03 & 0.07 & 0.00 & 0.22 \\
IgG $(\%)$ & 25.44 & 4.58 & 13.50 & 31.60 \\
\hline
\end{tabular}

Note: $\mathrm{LSBA}=$ litter size born alive, $\mathrm{ABWt}=$ average birth weight, $\mathrm{ADG}=$ average daily gain, $\mathrm{AWW}=$ average weaning weight, $\mathrm{PWM}=$ preweaning mortality, $\mathrm{IgG}=$ immunoglobulin content, $\mathrm{SD}=$ standard deviation, Min= minimum, Max = maximum .

Table 2. Descriptive statistics of 5 udder morphometries of Landrace $x$ Large White primiparous sows measured in different production stages $(\mathrm{N}=20)$

\begin{tabular}{|c|c|c|c|c|c|c|c|c|c|c|c|c|}
\hline \multirow{3}{*}{$\begin{array}{c}\text { Udder } \\
\text { morphometry } \\
(\mathrm{cm})\end{array}$} & \multicolumn{12}{|c|}{ Production stage } \\
\hline & \multicolumn{4}{|c|}{ Pre-Breeding } & \multicolumn{4}{|c|}{ Post-Breeding } & \multicolumn{4}{|c|}{ Post-Farrowing } \\
\hline & Mean & SD & Min & Max & Mean & SD & Min & Max & Mean & SD & Min & Max \\
\hline DIA & 10.68 & 1.02 & 8.00 & 14.00 & 11.10 & 0.96 & 10.00 & 14.60 & 10.94 & 0.51 & 9.80 & 12.30 \\
\hline LEN & 1.91 & 0.52 & 0.80 & 2.70 & 2.22 & 0.39 & 1.40 & 3.00 & 2.38 & 0.29 & 1.50 & 3.00 \\
\hline OPPR & 9.63 & 1.62 & 6.00 & 13.00 & 10.44 & 1.31 & 7.60 & 13.00 & 10.56 & 1.05 & 8.00 & 13.00 \\
\hline SAMER & 12.45 & 2.73 & 7.00 & 17.00 & 13.86 & 2.95 & 7.50 & 21.00 & 13.78 & 2.24 & 10.00 & 18.00 \\
\hline FLO & 26.46 & 3.91 & 21.00 & 40.00 & 25.48 & 4.14 & 20.00 & 40.00 & 25.29 & 3.05 & 21.00 & 30.00 \\
\hline
\end{tabular}

Note: $\mathrm{LEN}=$ length of the teat from the base to the tip, DIA= diameter of the teat tip, SAMER= inter-teat distance between adjacent teat bases in the same row, $\mathrm{OPPR}=$ distance between adjacent teats base in the opposite row, $\mathrm{FLO}=$ distance between the teat tip and the open floor, $\mathrm{SD}=$ standard deviation, Min= minimum, Max= maximum. 
Table 4. LS Means and standard error of five udder conformation traits in three different stages of primiparous Landrace $\mathrm{x}$ Large White gilts, according to udder symmetry and teat pair position $(\mathrm{cm})$

\begin{tabular}{|c|c|c|c|c|c|c|}
\hline Sources of variation & & DIA & LEN & OPPR & SAMER & FLO \\
\hline \multicolumn{7}{|l|}{ Pre-breeding } \\
\hline \multirow[t]{3}{*}{ Teat pair position } & Anterior & 10.50 & $1.76^{\mathrm{B}}$ & 9.54 & $11.30^{\mathrm{B}}$ & $24.10^{\mathrm{B}}$ \\
\hline & Posterior & 10.86 & $2.05^{\mathrm{A}}$ & 9.71 & $13.60^{\mathrm{A}}$ & $28.83^{\mathrm{A}}$ \\
\hline & p-value & $0.1126^{\mathrm{NS}}$ & 0.0119 & $0.6348^{\mathrm{NS}}$ & 0.0001 & $<0.0001$ \\
\hline \multirow[t]{5}{*}{ Udder symmetry } & Left & 10.57 & 1.95 & 9.58 & 12.48 & 26.30 \\
\hline & Right & 10.80 & 1.87 & 9.68 & 12.43 & 26.63 \\
\hline & $\mathrm{p}$-value & 0.3150 & 0.4794 & 0.7859 & 0.9295 & 0.6462 \\
\hline & SE & 0.16 & 0.08 & 0.26 & 0.40 & 0.50 \\
\hline & $\mathrm{CV}$ & 9.52 & 26.42 & 17.05 & 20.23 & 11.92 \\
\hline \multicolumn{7}{|l|}{ Post-breeding } \\
\hline \multirow[t]{3}{*}{ Teat pair position } & Anterior & 10.90 & $2.10^{\mathrm{B}}$ & 10.17 & $12.92^{\mathrm{B}}$ & $23.32^{\mathrm{B}}$ \\
\hline & Posterior & 11.30 & $2.33^{\mathrm{A}}$ & 10.72 & $14.80^{\mathrm{A}}$ & $27.64^{\mathrm{A}}$ \\
\hline & p-value & 0.0659 & 0.0084 & $0.0500^{\mathrm{NS}}$ & 0.0038 & $<0.0001$ \\
\hline \multirow[t]{5}{*}{ Udder symmetry } & Left & 11.10 & 2.22 & 10.66 & 14.01 & 24.73 \\
\hline & Right & 11.11 & 2.21 & 10.23 & 13.71 & 26.23 \\
\hline & $\mathrm{p}$-value & 0.9629 & 0.9045 & 0.1352 & 0.6355 & 0.0601 \\
\hline & SE & 0.15 & 0.06 & 0.20 & 0.45 & 0.55 \\
\hline & $\mathrm{CV}$ & 8.64 & 16.78 & 12.20 & 20.34 & 13.75 \\
\hline \multicolumn{7}{|l|}{ Post-farrowing } \\
\hline \multirow[t]{3}{*}{ Teat pair position } & Anterior & $10.64^{\mathrm{B}}$ & $2.21^{\mathrm{B}}$ & 10.65 & $12.30^{\mathrm{B}}$ & $22.85^{\mathrm{B}}$ \\
\hline & Posterior & $11.24^{\mathrm{A}}$ & $2.55^{\mathrm{A}}$ & 10.48 & $15.25^{\mathrm{A}}$ & $27.73^{\mathrm{A}}$ \\
\hline & p-value & $<0.0001$ & $<0.0001$ & 0.4593 & $<0.0001$ & $<0.0001$ \\
\hline \multirow[t]{5}{*}{ Udder symmetry } & Left & 10.95 & 2.36 & 10.38 & 13.90 & 25.78 \\
\hline & Right & 10.93 & 2.40 & 10.75 & 13.65 & 25.80 \\
\hline & $\mathrm{p}$-value & 0.8722 & 0.4464 & 0.1151 & 0.5026 & 0.0518 \\
\hline & SE & 0.07 & 0.04 & 0.17 & 0.26 & 0.28 \\
\hline & $\mathrm{CV}$ & 3.80 & 9.83 & 9.96 & 12.05 & 7.03 \\
\hline
\end{tabular}

Note: LEN= length of the teat from the base to the tip, DIA= diameter of the teat tip, SAMER= inter-teat distance between adjacent teat bases in the same row, $\mathrm{OPPR}=$ distance between adjacent teat base in the opposite row, FLO=distance between the teat tip and the open floor, means with different superscripts are significantly different $(\mathrm{p}<0.05), \mathrm{NS}=$ not significant.

morphometry, the pre-breeding stage of LEN in the posterior part was the best predictor of mothering ability. It explained $56 \%$ and $58 \%$ of the total variability in the ADG and AWWt, respectively. On the other hand, the post-breeding stage of SAMER in the anterior part explained $48 \%$ of the total variability in the levels of colostrum IgG. Moreover, the OPPR of posterior measured at the post-breeding stage explained $38 \%$ of the total variability in the LSBA.

Stepwise multiple regression analyses indicate that adding more udder morphometry increased the goodness of fit. For ADG and AWWt, adding three more udder morphometry, the proportion of total variability risen from $56 \%$ to $93 \%$, and $58 \%$ to $91 \%$, respectively. For the ABWt, the post-breeding stage of DIA in the anterior part and FLO in the posterior part explained 69\% of the total variability.

\section{DISCUSSION}

\section{Sources of Variation in Udder Morphometry of Primiparous Sows}

Teat diameter was also more uniform in Large White $x$ Landrace and Meidam sows compared to the other udder traits (Balzani et al. 2016c). In the current study, the CV values for LEN are comparable with the results of Balzani et al. (2016c). This simply indicated that in improving the sow udder morphometry, LEN and SAMER would then have a better chance than DIA. The study confirmed that the bilateral symmetry of the udder continues until farrowing. According to Propper et al. (2016), bilateral symmetry starts during the development of the mammary glands in the embryo period.

Across stages, the posterior teats had higher measurements than the anterior teat. These results are supported by the observation of Kim et al. (2000). According to them, mammary glands have different shapes: the anterior (first and second pairs) and middle (third, fourth and fifth pairs) of mammary glands grow laterally and medially, while the posterior glands (sixth, seventh, and eighth) expand elliptically in a longitudinal manner due to the space that they have to develop.

Moreover, breed and parity number cause variation in udder morphology. First and second parity sows had smaller teats and less developed udders compared with older multiparous animals (Balzani et al., 2016c). Consequently, teats of multiparous sows tend to have impaired teat access that can lead to increased piglet mortality (Vasdal \& Andersen, 2012). 
Table 5. Relationship of udder morphometry measured in different production stages to mothering ability

\begin{tabular}{|c|c|c|c|c|c|c|c|}
\hline \multirow{2}{*}{$\begin{array}{c}\text { Udder } \\
\text { morphometry }\end{array}$} & \multirow{2}{*}{$\begin{array}{l}\text { Teat pair } \\
\text { position }\end{array}$} & \multicolumn{6}{|c|}{ Mothering ability } \\
\hline & & LSBA & ABWt & ADG & AWWt & PWM & $\operatorname{IgG}$ \\
\hline \multicolumn{8}{|l|}{ Pre-breeding } \\
\hline \multirow[t]{2}{*}{ DIA } & Anterior & 0.15 & 0.06 & -0.16 & -0.13 & -0.20 & -0.48 \\
\hline & Posterior & -0.06 & 0.15 & -0.01 & 0.02 & -0.27 & 0.03 \\
\hline \multirow[t]{2}{*}{ LEN } & Anterior & -0.25 & -0.05 & -0.29 & -0.29 & -0.26 & -0.13 \\
\hline & Posterior & 0.09 & -0.23 & -0.06 & -0.10 & -0.18 & -0.16 \\
\hline \multirow[t]{2}{*}{ OPPR } & Anterior & 0.44 & -0.23 & $-0.50^{*}$ & $-0.51^{*}$ & -0.14 & -0.43 \\
\hline & Posterior & 0.17 & 0.04 & -0.30 & -0.29 & -0.40 & 0.07 \\
\hline \multirow[t]{2}{*}{ SAMER } & Anterior & 0.18 & 0.05 & 0.05 & 0.03 & -0.34 & 0.12 \\
\hline & Posterior & 0.10 & 0.02 & -0.20 & -0.21 & -0.31 & -0.17 \\
\hline \multirow[t]{2}{*}{ FLO } & Anterior & 0.26 & 0.15 & $-0.49^{*}$ & $-0.45^{*}$ & 0.10 & -0.26 \\
\hline & Posterior & 0.04 & 0.31 & -0.30 & -0.25 & -0.07 & 0.33 \\
\hline \multicolumn{8}{|l|}{ Post-breeding } \\
\hline \multirow[t]{2}{*}{ DIA } & Anterior & 0.19 & 0.07 & -0.21 & -0.18 & -0.08 & -0.48 \\
\hline & Posterior & 0.23 & 0.08 & -0.24 & -0.21 & 0.12 & -0.10 \\
\hline \multirow[t]{2}{*}{ LEN } & Anterior & 0.13 & -0.10 & 0.04 & 0.01 & -0.10 & -0.20 \\
\hline & Posterior & 0.02 & -0.13 & 0.30 & 0.26 & -0.01 & -0.05 \\
\hline \multirow[t]{2}{*}{ OPPR } & Anterior & 0.30 & -0.32 & -0.31 & $0-0.32$ & 0.40 & 0.02 \\
\hline & Posterior & $0.47^{*}$ & $-0.55^{*}$ & -0.19 & -0.27 & 0.08 & -0.12 \\
\hline \multirow[t]{2}{*}{ SAMER } & Anterior & 0.02 & 0.02 & 0.20 & 0.18 & -0.07 & $0.69^{* *}$ \\
\hline & Posterior & 0.38 & -0.34 & -0.12 & -0.17 & 0.09 & 0.37 \\
\hline \multirow[t]{2}{*}{ FLO } & Anterior & 0.15 & 0.22 & -0.30 & -0.25 & -0.11 & $-0.64^{*}$ \\
\hline & Posterior & -0.02 & 0.28 & 0.01 & 0.05 & -0.16 & -0.35 \\
\hline \multicolumn{8}{|l|}{ Post-farrowing } \\
\hline \multirow[t]{2}{*}{ DIA } & Anterior & -0.08 & 0.41 & 0.06 & 0.11 & 0.07 & 0.16 \\
\hline & Posterior & -0.30 & 0.41 & -0.25 & -0.18 & 0.05 & -0.17 \\
\hline \multirow[t]{2}{*}{ LEN } & Anterior & 0.40 & 0.10 & $-0.53^{*}$ & $-0.50^{*}$ & 0.18 & -0.07 \\
\hline & Posterior & 0.08 & 0.28 & -0.31 & -0.27 & -0.25 & -0.23 \\
\hline \multirow[t]{2}{*}{ OPPR } & Anterior & -0.05 & -0.23 & -0.25 & -0.26 & 0.42 & 0.07 \\
\hline & Posterior & 0.19 & 0.15 & -0.35 & -0.34 & 0.04 & 0.19 \\
\hline \multirow[t]{2}{*}{ SAMER } & Anterior & -0.24 & -0.27 & 0.45 & 0.39 & 0.18 & 0.06 \\
\hline & Posterior & 0.00 & 0.00 & -0.09 & -0.09 & -0.34 & -0.23 \\
\hline \multirow[t]{2}{*}{ FLO } & Anterior & $0.60^{* *}$ & -0.04 & $-0.62^{* *}$ & $-0.60^{* *}$ & 0.28 & 0.27 \\
\hline & Posterior & -0.29 & -0.05 & 0.43 & 0.40 & -0.18 & $-0.53^{*}$ \\
\hline
\end{tabular}

Note: $\mathrm{LEN}=$ length of the teat from the base to the tip, DIA= diameter of the teat tip, SAMER= inter-teat distance between adjacent teat bases in the same row, OPPR = distance between adjacent teat base in the opposite row, $\mathrm{FLO}=$ distance between the teat tip and the open floor, LSBA= litter size born alive, $\mathrm{ABWt}=$ average birth weight $(\mathrm{kg}), \mathrm{ADG}=$ average daily gain $(\mathrm{kg} / \mathrm{d}), \mathrm{AWWt}=$ average weaning weight $(\mathrm{kg}), \mathrm{PWM}=\mathrm{pre}-\mathrm{weaning}$ mortality $(\%), \operatorname{IgG}=$ immunoglobulin content $(\%),{ }^{*}-\mathrm{p}<0.05 ;{ }^{* *}-\mathrm{p}<0.01$.

Table 6. Prediction model for mothering ability using the pre-breeding (PreB) and post-breeding (PostB) udder morphometries

\begin{tabular}{lcc}
\hline \multicolumn{1}{c}{ Model } & R $^{2}$ & RMSE \\
\hline LSBA $=$ 28.22 + 0.90 (PreB_F_SAMER) -0.10 (PreB_R_FLO) & 0.59 & 1.91 \\
LSBA $=-4.98+1.37$ (PostB_R_OPPR) & 0.38 & 2.18 \\
ABWt $=2.55-0.29$ (PostB_F_DIA) + 0.08 (PostB_R_FLO) & 0.69 & 0.16 \\
ADG $=0.45-0.10$ (PreB_R_LEN) & 0.56 & 0.06 \\
ADG $=0.26+0.16$ (PostB_F_LEN) + 0.08 (PreB_F_LEN) - 0.34 (PreB_R_LEN) + 0.02 (PreB_R_SAMER) & 0.93 & 0.05 \\
AWWt $=15.38-3.04$ (PreB_R_LEN) & 0.58 & 1.73 \\
AWWt $=-9.78+0.66$ (PostB_R_FLO) & 0.32 \\
AWWt $=10.15+4.63$ (PostB_F_LEN) + 2.94 (PreB_F_LEN) - 10.62 (PreB_R_LEN) + 0.50 (PreB_R_SAMER) & 0.91 \\
IgG $=$ 6.41 + 1.40 (PostB_F_SAMER) & 0.74 \\
\hline
\end{tabular}

Note: LEN= length of the teat from the base to the tip, DIA= diameter of the teat tip, SAMER= inter-teat distance between adjacent teat bases in the same row, OPPR = distance between adjacent teat base in the opposite row, FLO=distance between the teat tip and the open floor, LSBA= litter size born alive, $\mathrm{ABW}=$ average birth weight, $\mathrm{ADG}=$ average daily gain, $\mathrm{AWWt}=$ average weaning weight, $\mathrm{IgG}=\mathrm{immunoglobulin}$ content, PreB= Pre-breeding stage, Post $\mathrm{B}=$ Post-breeding stage, $\mathrm{F}=$ Front, $\mathrm{R}=$ Rear, $\mathrm{R}^{2}=$ coefficient of determination, $\mathrm{RMSE}=$ root mean square error. 


\section{Relationship of Post-Farrowing Udder Morphometry to Mothering Ability}

The correlations of LEN and FLO in the anterior part with pre-weaning ADG and litter weaning weight conform to the observation of Balzani et al. (2016a). They observed a negative correlation between udder morphometric traits and litter weight gain at ten days. According to them, large udder size undesirably affects nursing pig performance due to impaired teat access. The current study suggests that sows with higher litter sizes will have udder in the anterior part characterized by longer teat tip to floor distance. These results are contradictory to the observations of Balzani et al. (2016a), where they found a positive correlation between pre-weaning mortality and DIA. They further suggested that the teat size could be linked to the mortality of piglets.

The relationship of colostrum IgG content and FLO in the posterior part suggests that, in the posterior part, udders that are close to the floor tend to have a higher concentration of colostrum IgG. Moreover, Ogawa et al. (2014) noted that higher colostrum yield tends to contain more IgG. The result is in contrast to the other report where the teat pair position has been associated with colostrum yield showing that the anterior and middle teats seemed to have a larger production than posterior ones (Fraser \& Rushen, 1992). A more recent study confirmed this evidence, showing that anterior and middle mammary glands produce more colostrum and milk than posterior mammary glands (Kim et al., 2000). However, ambiguous results were also found about the relationship between teat position and colostrum immunoglobulin content: anterior (Wu et al., 2010), and posterior (Klobasa et al., 1987). Furthermore, the colostrum IgG level is multifactorial and that the quality of colostrum is influenced by the overall health status of the sow and its exposure to disease and/or vaccination.

Teat preference is a cause of strong disputes among littermates, as anterior udders are more preferred (Kim et al., 2000). Vasdal \& Andersen (2012) noticed that access to the lower teat row during nursing is always more limited than the upper row. It is speculated that there is an optimum size for suckling; and, if the teat size is large the piglet will have difficulty in suckling and eventually will lead to greater mortality.

\section{Prediction Equation}

Selecting replacement gilts based on their future mothering abilities is very difficult and time-consuming. However, most genetic selection in dam lines is mainly focused on production and reproduction traits. Consequently, evaluation of the mothering ability of the sows using udder morphometry is an unexplored field. Thus, the study evaluated the possibility of predicting the mothering ability of replacement gilt using its udder morphometry.

Among the udder measurements in the pre-breeding and post-breeding stages, the pre-breeding posterior teat length has the potential to be a predictor of some mothering ability. It is suggested that this trait can be added as a criterion for the physical selection of replacement gilts. Moreover, to have a higher accuracy of predicting the ADG and AWWt, combined measurement of pre-breeding and post-breeding udder morphometric traits should be used.

To our knowledge, this is the first study to explore the possibility of predicting the sow mothering ability with primiparous udder morphometric traits. By selecting gilts based on their udder morphometry, it will lead to the generation of animals with better mothering ability (Balzani et al., 2016b). Moreover, including udder quality traits in the selection program can be considered as worthy of promotion (Olesen et al., 2000). However, more investigations must be undertaken to further study the relationship between these morphology traits and the piglets' suckling behavior and performance.

\section{CONCLUSION}

The pre-breeding combined with post-breeding udder morphometry measurements in gilts is useful as a predictor of sow mothering ability. These traits can be included in the criteria when selecting replacement gilts to enhance the productivity of sow herd.

\section{CONFLICT OF INTEREST}

The authors declare that there is no conflict of interest with any financial, personal, or other relationships with other people or organizations related to the material discussed in the manuscript.

\section{ACKNOWLEDGEMENT}

The authors would like to acknowledge and thank PhilNutri, Inc., for the support rendered in the conduct of this study.

\section{REFERENCES}

Balzani, A., H. Cordell, \& S. Edwards. 2015. Development of a methodology to describe udder conformation in sows. Animal 10: 432-439. https://doi.org/10.1017/ S1751731115002347

Balzani, A., H. Cordell, \& S. Edwards. 2016a. Relationship of sow udder morphology with piglet suckling behavior and teat access. Theriogenology 86: 1913-1920. https://doi. org/10.1016/j.theriogenology.2016.06.007

Balzani, A., H. Cordell, \& S. Edwards. 2016b. Heritability of udder morphology and colostrum quality traits in swine. J. Anim. Sci. 94: 3636-3644. https://doi.org/10.2527/ jas.2016-0458

Balzani, A., H. Cordell, E. Sutcliffe, \& S. Edwards. 2016c. Sources of variation in udder morphology of sows. J. Anim. Sci. 94: 394-400. https://doi.org/10.2527/jas.2015-9451

Chalkias H., L. Rhydhmer, \& N. Lundeheim. 2013. Genetic analysis of functional and non-functional teats in a population of Yorkshire pigs. Livest. Sci. 152: 127-134. https:// doi.org/10.1016/j.livsci.2013.01.003

Farmer, C., E. Fortin, \& S. Méthot. 2017. In vivo measures of mammary development in gestating gilts. J. Anim. Sci. 95: 5358-5364. https://doi.org/10.2527/jas2017.1768

Fraser, D. \& J. Rushen. 1992. Colostrum intake by newborn piglets. Can. J. Anim. Sci. 72: 1-13. https://doi.org/10.4141/ cjas92-001 
Huntley, S.J., S. Cooper, A.J. Bradley, \& L.E. Green. 2012. A cohort study of the associations between udder conformation, milk somatic cell count, and lamb weight in suckler ewes. J. Dairy Sci. 95: 5001-5010. https://doi.org/10.3168/ jds.2012-5369

Kim S.W., W.L. Hurley, I.K. Hant, \& R.A. Easter. 2000. Growth of nursing pigs related to the characteristics of nursed mammary glands. J. Anim. Sci. 78:1313-1318. https://doi. org $/ 10.2527 / 2000.7851313 x$

Klobasa F., E. Werhahn, \& J.E. Butler. 1987. Composition of sow milk during lactation. J. Anim. Sci. 64: 8-10. https:// doi.org/10.2527/jas1987.6451458x

Koketsu Y., S. Tani, \& R. Iida. 2017. Factors for improving reproductive performance of sows and herd productivity in commercial breeding herds. Porc. Health Manag. 3, 1 (2017). https://doi.org/10.1186/s40813-016-0049-7

Kouri, F., S. Charallah, A. Kouri, Z. Amirat, \& F. Khammar. 2018. Milk production and its relationship with composition, body and udder morphological traits in Bedouin goat reared under arid conditions. Acta Sci. Anim. Sci. 41. https://doi.org/10.4025/actascianimsci.v41i1.42552

Norsvin. 2014. The annual report from the Norwegian Swine Breeding Organization: http://www.norsvin.lt/ Genetic-Program/Breeding-Goals.

Ocepek, M., I. Andersen-Ranberg, S.A. Edwards, \& I.L. Andersen. 2016. Udder characteristics of importance for teat use in purebred and crossbred pigs. J. Anim. Sci. 94:780-788. https://doi.org/10.2527/jas.2015-9420

Ogawa, S., T. Tsukahara, R. Nishibayashi, M. Nakatani, M. Okutani, N. Nakanishi, K. Ushida, \& R. Inoue. 2014. Shotgun proteomic analysis of porcine colostrum and mature milk. Anim. Sci. J. 85: 440-448. https://doi.org/10.1111/ asj.12165
Olesen, I., A.F. Groen, \& B. Gjerde. 2000. Definition of animal breeding goals for sustainable production systems. J. Anim. Sci. 78: 570-582.

Patterson, J. \& G. Foxcroft. 2019. Gilt management for fertility and longevity. Animals, 9:434. https://doi.org/10.3390/ ani9070434

PHILSAN. 2010. Feed Reference Standards. 4th Edition. Philippine Society of Animal Nutritionists.

Propper, A.Y., B.A. Howard, \& J.M. Veltmaat. 2016. Prenatal morphogenesis of mammary glands in mouse and rabbit. J. Mammary Gland Biol. Neoplasia 18: 93-104. https://doi. org/10.1007/s10911-013-9298-0

Rydhmer, L. 2000. Genetics of sow reproduction, including puberty, oestrus, pregnancy, farrowing and lactation. Livest. Prod.Sci. 66: 1-12. https://doi.org/10.1016/ S0301-6226(99)00170-0

SAS. 2016. SAS University Edition. SAS Institute, Cary NC.

Vasdal, G. \& I.L. Andersen. 2012. A note on teat accessibility and sow parity - consequences for newborn piglets. Livest. Sci. 146: 91-94. https://doi.org/10.1016/j.livsci.2012.02.005

Wu, W.Z., X.Q. Wang, G.Y. Wu, S.W. Kim, F. Chen, \& J.J. Wang. 2010. Differential composition of proteomes in sow colostrum and milk from anterior and posterior mammary glands. J. Anim. Sci. 88: 2657-2664. https://doi.org/10.2527/ jas.2010-2972

Zwertvaegher, I., J. Baert, J. Vangeyte, A. Genbrugge, \& S. Van Weyenberg. 2011. Objective measuring technique for teat dimensions of dairy cows. Biosyst. Eng., 110: 206-212. https://doi.org/10.1016/j.biosystemseng.2011.08.009 